\title{
Modeling the influence of wave-enhanced turbulence in a shallow tide- and wind-driven water column
}

\author{
Nicole L. Jones ${ }^{1,2}$ and Stephen G. Monismith ${ }^{1}$ \\ Received 27 March 2007; revised 14 August 2007; accepted 2 November 2007; published 11 March 2008.
}

[1] The ability of one-dimensional hydrodynamic models to reproduce dissipation of turbulent kinetic energy and velocity profiles for conditions of whitecapping waves in a shallow water, tide- and wind-forced environment was assessed. The models were forced with the conditions experienced during a month-long field experiment in a shallow estuarine embayment, and the results were compared with the observed dissipation and mean velocity profiles. Three turbulence models were assessed: the $k$ - $\omega$ model and two $k-l$ models, with different prescribed bilinear relationships for the turbulent length scale, $l$. The $k-\omega$ turbulence model was found to best replicate the measured decay of dissipation with depth with a surface roughness length, $z_{0 s}=1.3 H_{s}$, and wave energy parameter, $\alpha=60$. The $k$ - $l$ model achieved equally as good reproduction of the observations as the $k-\omega$ model when the proportionality constant in the prescribed linear length scale relationship for the upper half of the water column was modified from the traditionally employed von Karman's constant, $\kappa=0.4$, to 0.25 . The model results show that the whitecapping waves often supplied the dominant source of turbulent kinetic energy over the majority of the water column in the shallow, tide- and wind-forced system.

Citation: Jones, N. L., and S. G. Monismith (2008), Modeling the influence of wave-enhanced turbulence in a shallow tide- and wind-driven water column, J. Geophys. Res., 113, C03009, doi:10.1029/2007JC004246.

\section{Introduction}

[2] Breaking waves produce levels of turbulent kinetic energy dissipation, $\varepsilon$, in the surface water column that can be orders of magnitude larger than that produced directly by shear resulting from a wind stress [e.g., Soloviev and Lukas, 2003; Terray et al., 1996]. Furthermore, measurements demonstrate that in shallow water, elevated $\varepsilon$ extends over large portions of the water column under conditions of a large wind stress [Feddersen et al., 2007; Jones and Monismith, 2008; Young et al., 2005].

[3] A number of studies have focused on creating a onedimensional (1-D), two-equation turbulence closure model that best reproduces field measurements under conditions of whitecapping waves [e.g., Burchard, 2001; Craig, 1996; Craig and Banner, 1994; Stips et al., 2005; Umlauf and Burchard, 2003; Umlauf et al., 2003]. A variety of twoequation turbulence closure models exist; these include the Mellor and Yamada [1982] model, which solves equations for the turbulent kinetic energy, $k$, and its product with the turbulent length scale, $l$; the $k-\varepsilon$ model [Rodi, 1987], which solves equations for $k$ and for the rate of dissipation, $\varepsilon$; and the $k$ - $\omega$ model [Wilcox, 1988], which solves equations for $k$ and the inverse timescale or turbulent "frequency", $\omega$. All

\footnotetext{
${ }^{1}$ Environmental Fluid Mechanics Laboratory, Department of Civil and Environmental Engineering, Stanford University, Stanford, California, USA.

${ }^{2}$ Now at School of Environmental Systems Engineering, University of Western Australia, Crawley, Western Australia, Australia.

Copyright 2008 by the American Geophysical Union. 0148-0227/08/2007JC004246\$09.00
}

three of these turbulence closure models have been used in the past to simulate the effect of whitecapping in deep water.

[4] Craig and Banner [1994] applied the Mellor and Yamada [1982] model with a prescribed bilinear relationship for $l$ with a slope equal to von Karman's constant, $\kappa=0.4$, analogous to the law of the wall. Craig and Banner [1994] demonstrated that the model is able to reproduce the field $\varepsilon$ measurements of Agrawal et al. [1992], Anis and Moum [1992], and Osborn et al. [1992] reasonably well. Noting that the Craig and Banner [1994] model did not account for the high dissipation values close to the water surface observed in the SWADE [Drennan et al., 1996] and WAVES [Terray et al., 1996] data sets Terray et al. [1999] presented a modified expression for the turbulent length scale. The alternate length scale model assumed a constant length scale to the depth of the surface roughness, $z_{0 s}$, below this the length scale increased linearly to the midwater column with a slope of $\kappa$.

[5] The $k-\varepsilon$ model was adapted by Burchard [2001] to simulate the dynamics of the wave-enhanced surface layer. Burchard [2001] created a variable turbulent Schmidt number, $\sigma_{\varepsilon}$, for the $\varepsilon$ equation in order to generalize the $k-\varepsilon$ model to reproduce both the wave enhanced boundary layer and the law-of-the-wall layer beneath it. To determine how $\sigma_{\varepsilon}$ varied Burchard [2001] solved the $\varepsilon$ equation with the steady state analytical solution for $k$ and $\varepsilon$ resulting from the Craig and Banner [1994] model (as derived by Craig [1996]) [see Burchard, 2001, Figure 1]. This means that the solution of the $k-\varepsilon$ model corresponds to the simpler model of Craig and Banner [1994] as the linear turbulent length scale relation is effectively assumed to hold in the wave enhanced layer. 
[6] The efficacy of using the $k-\omega$ turbulence closure model for simulating the wave enhanced surface layer was explored by Umlauf et al. [2003]. Umlauf et al. [2003] found that the Wilcox [1988] form of the $k-\omega$ model reproduced measurements of shear-free turbulence (from oscillating grid experiments) as well as attaining good agreement with the WAVES, SWADE, and Anis and Moum [1995] $\varepsilon$ data sets without modification. Furthermore, Umlauf et al. [2003] showed that under conditions of shear-free turbulence the $k$ - $\omega$ model yields a turbulent length scale that increases linearly with depth with the constant of proportionality equal to 0.25 . This proportionality constant is almost half the magnitude of $\kappa$, which was used by Craig and Banner [1994] and Terray et al. [1999].

[7] Common to all of these models is the parameterization of the flux of turbulent kinetic energy (TKE) at the surface used to simulate the influence of wave breaking. Following Kundu [1980], the surface TKE flux is parameterized as $\alpha u^{3}{ }^{3}$, where $\alpha$ is a constant argued to be dependent on the wave age [Terray et al., 1996]. Constant values of $\alpha$ have generally been employed in models e.g., $\alpha=100$ [Craig and Banner, 1994] and $\alpha=150$ [Stacey, 1999]. Field studies have also quantified $\alpha$; Feddersen et al. [2007] found that $\alpha=250$ best described their nearshore measurements and Jones and Monismith [2008] found $\alpha=$ 60 best described their shallow estuary measurements.

[8] The second parameter that influences the distribution of TKE close to the surface is the water column surface roughness, $z_{0 s}$. This parameter has been assumed to be of the same order as the depth of direct injection of turbulence by breaking waves [Terray et al., 1996]. Measurements of this value are difficult and therefore scarce. Rapp and Melville [1990] found that the bubble entrainment depth was approximately equal to the wave height. The fine structure temperature measurements of Gemmrich and Farmer [1999] led them to conclude that $z_{0 s}$ was approximately $0.2 \mathrm{~m}$ under conditions of very large significant wave heights, $H_{s}=3.5 \mathrm{~m}$.

[9] Various numerical model studies have defined $z_{0 s}$ by adjusting the parameter to achieve the best agreement between the model output and measurements. The successful collapse of $\varepsilon$ measurements with both $H_{s}$ and the peak wave number, $k_{p}$, to nondimensionalize the distance below the water surface has led to these two wave parameters being popular choices for defining $z_{0 s}$ [e.g., Jones and Monismith, 2008; Terray et al., 1996]. Soloviev and Lukas [2003] found $z_{0 s}=0.6 H_{s}$ using a Craig and Banner [1994] style model and Terray et al. [1999] found that $z_{0 s}=0.85 H_{s}$ with their modified length scale Craig and Banner [1994] style model. Burchard [2001] found that simulations with a $k-\varepsilon$ turbulence model with $z_{0 s} / H_{s}$ between 0.25 and 1 encompassed the WAVES [Terray et al., 1996] and SWADE [Drennan et al., 1996] data sets. Umlauf et al. [2003] found that the $k-\omega$ model with $z_{0 s}=H_{s}$ best reproduced the SWADE and WAVES data sets.

[10] Other studies have related the surface roughness to the surface shear velocity, $u_{*_{w}}$, employing an adapted Charnock formula [Munk et al., 1955],

$$
z_{0 s}=a_{s} u_{*_{w}}^{2} / g
$$

Here $g$ is gravity and $a_{s}$ is a dimensionless parameter that has been assumed to take various magnitudes. In the absence of breaking waves, $a_{s}$ is commonly assumed to have a magnitude of 1400 [e.g., Craig and Banner, 1994; Ly and Garwood, 2000]. When extended to a wave breaking scenario Stips et al. [2005] found that $a_{s}=14000$ led to the best possible reproduction of their lake data set. In a 2-D numerical model of a fjord, Stacey [1999] found that $a_{s}=$ $\mathrm{O}\left(10^{5}\right)$ was appropriate. Furthermore, Stacey [1999] showed that, for the conditions in the fjord, assuming $a_{s}=$ $O\left(10^{5}\right)$ was consistent with $z_{0 s}=\mathrm{O}\left(H_{s}\right)$.

[11] Only one study has used near surface mean velocity measurements to estimate $z_{0 s}$. By comparing the laboratory data set of Cheung and Street [1988] to the results of the turbulence closure model of Craig and Banner [1994], Craig [1996] found that $z_{0 s}$ is proportional to the peak wavelength, $z_{0 s} \sim \lambda_{p} / 6$. However, Craig [1996] also demonstrated analytically that $z_{0 s}$ is sensitive to the choice of $\alpha$; for example, increasing $\alpha$ from 100 to 150 resulted in a decrease in the estimate of $z_{0 s}$ by a factor of 0.88 .

[12] In the present study the ability of the Craig and Banner [1994] style (with standard and modified [Terray et $a l .$, 1999] length scale formulations) and the $k-\omega$ (as presented by Umlauf et al. [2003]) turbulence models to reproduce $\varepsilon$ and mean velocity profiles for a shallow water, tide- and wind-forced environment was assessed. The turbulence models were forced with the conditions experienced during a month-long field experiment in a shallow estuarine embayment [Jones and Monismith, 2008] and the results compared with the extensive set of observed $\varepsilon$ and mean velocity profiles. The $k-\omega$ turbulence model was then used to investigate the vertical structure of the turbulence and mean flow properties, thereby allowing the depth of influence of the breaking waves to be identified.

\section{Methods}

\subsection{Field Measurements}

[13] The measurements were made in Grizzly Bay, San Francisco Bay, California (Figure 1), from 1 May to 2 June 2005. Grizzly Bay is a subembayment of Suisun Bay, covering approximately $24 \mathrm{~km}^{2}$. The tides are semidiurnal with a range of approximately $2 \mathrm{~m}$ in this area. Depthaveraged maximum currents at the measurement location were approximately $-0.15 \mathrm{~m} \mathrm{~s}^{-1}$ on ebb and $0.25 \mathrm{~m} \mathrm{~s}^{-1}$ on flood. The mean depth at the measurement site was approximately $2.5 \mathrm{~m}$.

[14] The experimental site was located approximately in the center of the embayment (Figure 1). An array of four acoustic Doppler velocimeters (ADVs) (Vector, Nortek AS) recorded velocity and pressure at four heights above the bed $(\mathrm{ADV} 1=0.15 \mathrm{~m}, \mathrm{ADV} 2=0.5 \mathrm{~m}, \mathrm{ADV} 3=1.5 \mathrm{~m}$ and ADV4 $=2 \mathrm{~m}$ ). The ADVs were sampled for a period of 10 minutes at $16 \mathrm{~Hz}$ every 30 minutes. A vertical array of five thermistors (SBE39, Seabird) and two conductivity sensors (SBE16+, Seabird) were used to identify any periods of stratification. A wind anemometer (Wind monitor model 05103, R. M. Young Company), situated approximately $6 \mathrm{~m}$ above the mean water level, recorded wind velocity statistics every 10 minutes, including average wind speed and direction. 


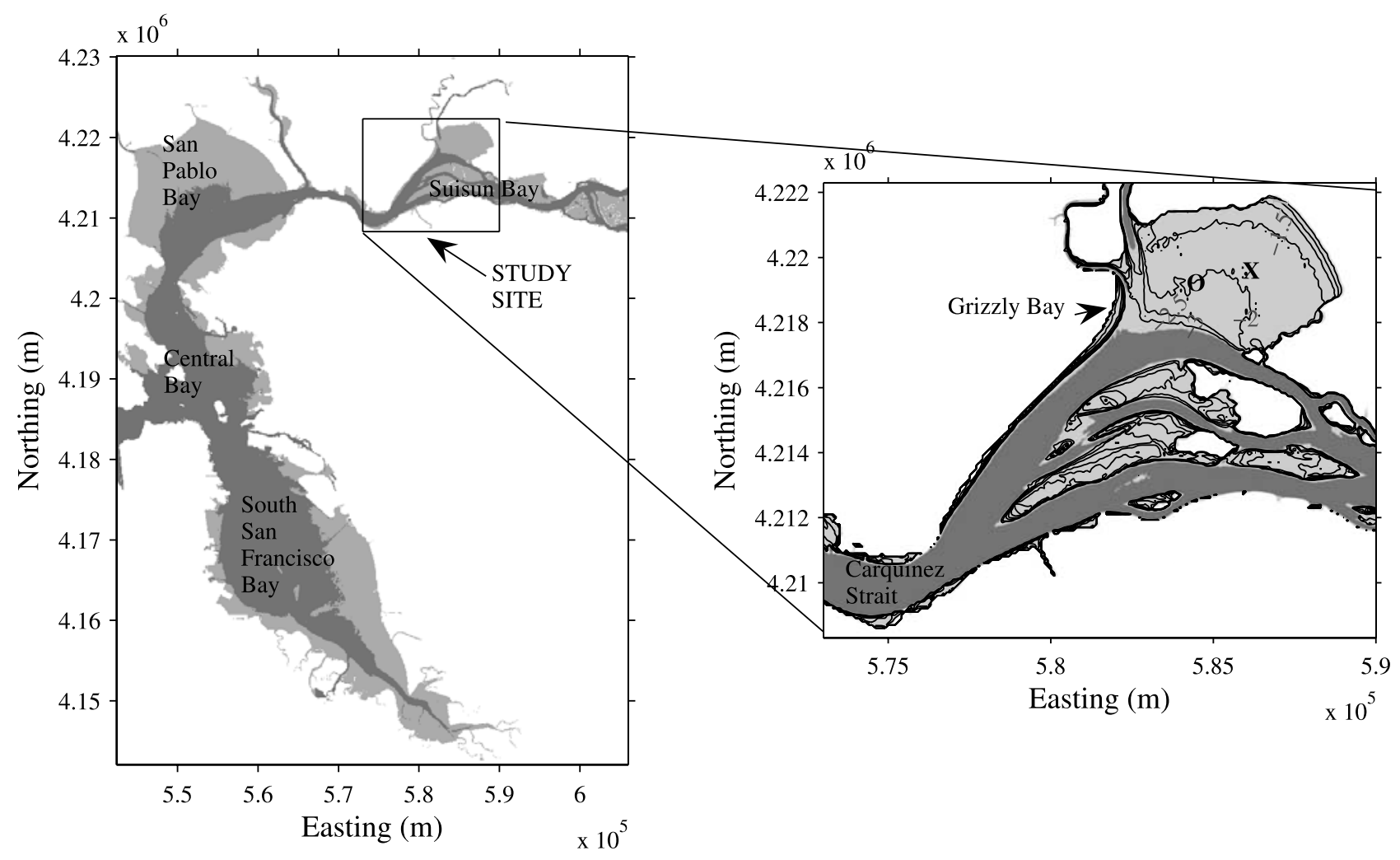

Figure 1. Bathymetric contours and site map of Suisun Bay showing location of ADV frame (cross) and wind anemometer and camera platform (open circle). The darker gray areas indicate depth greater than $4 \mathrm{~m}$.

[15] The $10 \mathrm{~m}$ wind speed and wind stress were estimated from the measured wind velocity via the Donelan [1990] algorithm, which was developed for fetch-limited lakes, and accounts for the effect of waves and whitecapping on the wind stress. Wave height and period were calculated from the pressure records of the ADVs [Jones and Monismith, 2007].

[16] $\varepsilon$ was calculated from the 10 minute ADV records via $a-5 / 3$ fit to the inertial subrange of the vertical velocity spectra, beyond the wave peak, employing the Lumley and Terray [1983] model to account for the effects of waves on the turbulent wave number spectrum. The method detailed by Feddersen et al. [2007] was used. This method numerically evaluates the form of the TKE spectra for turbulence advected by both oscillatory and unidirectional velocities. The Reynolds stress at $0.15 \mathrm{~m}$ above the bed was calculated from the ADV data using the wave turbulence decomposition method presented by Feddersen and Williams [2007].

[17] For the measurement period the prevailing winds were generally from the southwest and west and displayed a diurnal pattern in strength. The most frequently observed wind speed was $7 \mathrm{~m} \mathrm{~s}^{-1}$ and wind speeds up to $15 \mathrm{~m} \mathrm{~s}^{-1}$ were observed. The waves had a mean period, $T_{m}$, varying from 1 to $1.6 \mathrm{~s}$ and significant wave height, $H_{s}$, from 0 to $0.6 \mathrm{~m}$. The experimental conditions resulted in predominantly intermediate depth wind seas, as defined by linear wave theory, having a mean nondimensional depth, $k_{p} h=$ 2.2 (where $k_{p}$ is the peak wave number). The wave age (peak wave phase speed normalized by the wind shear stress, $c_{p} / u_{*}$ ) ranged from 5 to 15 , indicating young to moderately developed waves.
[18] Weak wind stress periods coincident with strong positive heat fluxes led to some periods of thermal stratification which persisted for between 2 and $6 \mathrm{~h}$. In total, 14\% of the observations were during stable stratification events.

\subsection{Model Description}

[19] The hydrodynamic model used was the Global Ocean Turbulence Model [Burchard, 2001; Burchard and Petersen, 1999; Umlauf and Burchard, 2003, 2005; Umlauf et al., 2003]. The mathematical models on which the simulations were based consist of four dynamical equations. The equations for the Reynolds averaged velocities, $u$ and $v$, and turbulent kinetic energy, $k$, are common to all three models. The fourth equation differs for each of the models (sections 2.2.1-2.2.3). Assuming negligible horizontal gradients, negligible vertical velocities and that buoyancy production is insignificant, the first three equations are

$$
\begin{gathered}
\frac{\partial u}{\partial t}-\frac{\partial}{\partial z}\left(\nu_{t}+\nu\right) \frac{\partial u}{\partial z}=-\frac{g}{\rho_{0}} \frac{\partial p}{\partial x} \\
\frac{\partial v}{\partial t}-\frac{\partial}{\partial z}\left(\nu_{t}+\nu\right) \frac{\partial v}{\partial z}=-\frac{g}{\rho_{0}} \frac{\partial p}{\partial y} \\
\frac{\partial k}{\partial t}-\frac{\partial}{\partial z} \nu_{k} \frac{\partial k}{\partial z}=\nu_{t}\left(\left(\frac{\partial u}{\partial z}\right)^{2}+\left(\frac{\partial v}{\partial z}\right)^{2}\right)-\varepsilon .
\end{gathered}
$$


Here $z$ is the vertical coordinate, measured positive upward from the seabed, $z=0$ to the surface, $z=h, t$ is time, $\nu$ is the kinematic viscosity, $g$ is gravity and $\rho_{0}$ is the density. The shear production term (term 1, right-hand side of equation (4) and transport terms (term 2, left-hand side of equation (4)) are expressed by simple gradient formulations, where $\nu_{t}$ is the eddy viscosity and $\nu_{k}$ is a similar parameter, resulting from the gradient transport model used to describe the transport and pressure-diffusion terms. The eddy viscosity is defined as

$$
\nu_{t}=c_{\mu}^{0} k^{1 / 2} l,
$$

where $l$ is the turbulent length scale

$$
l=\left(c_{\mu}^{0}\right)^{3} \frac{k^{3 / 2}}{\varepsilon}
$$

where $c_{\mu}^{0}$ was assumed to be a constant. The parameter $\nu_{k}$ is defined as

$$
\nu_{k}=\frac{\nu_{t}}{\sigma_{k}}
$$

where $\sigma_{k}$ is a constant.

[20] The surface boundary conditions for the momentum equations are

$$
\nu_{t} \frac{\partial u}{\partial z}=u_{*_{w}}^{2} ; \quad \nu_{t} \frac{\partial v}{\partial z}=v_{*_{w}}^{2}
$$

and under whitecapping conditions the $k$ equation surface boundary condition is

$$
\nu_{k} \frac{\partial k}{\partial z}=\alpha\left(u_{*_{w}}^{2}+v_{*_{w}}^{2}\right)^{3 / 2}
$$

In the absence of whitecapping the $k$ equation surface boundary condition is

$$
\nu_{k} \frac{\partial k}{\partial z}=0
$$

At the bed the boundary conditions for momentum

$$
\nu_{t} \frac{\partial u}{\partial z}=u_{*_{b}}^{2} ; \quad \nu_{t} \frac{\partial v}{\partial z}=v_{*_{b}}^{2}
$$

and the $k$ equation

$$
\nu_{k} \frac{\partial k}{\partial z}=0
$$

are applied. Here $\left(u_{* b}, v_{*_{b}}\right)$ is the shear velocity at the bed.

[21] The fourth equation is the difference in the formulation of the models and will be presented for each model in sections 2.2.1-2.2.3.

\subsubsection{Craig and Banner Model}

[22] The Craig and Banner [1994] model is based on the Mellor and Yamada [1982] model with a prescribed bilinear relationship for the turbulent length scale, $l$, analogous to the law of the wall

$$
\begin{aligned}
l & =\kappa\left(-z+z_{0 s}+h\right), & & \left(h+z_{0 s}-z_{0 b}\right) / 2 \leq z \leq h \\
& =\kappa\left(z+z_{0 b}\right), & & 0 \leq z \leq\left(h+z_{0 s}-z_{0 b}\right) / 2
\end{aligned},
$$

where $h$ is the height of the water column and $z_{0 b}$ is the bed roughness. The empirical constants, $c_{\mu}^{0}=0.55$ and $\sigma_{k}=$ 1.96, from Mellor and Yamada [1982] were used in equations (5)-(7).

\subsubsection{Modified Craig and Banner Model}

[23] The Terray et al. [1999] model is identical to the Craig and Banner [1994] model with the exception of the prescribed length scale. The alternate length scale model is

$$
\begin{aligned}
l & =\kappa z_{0 s}, & & h-z_{0 s} \leq z \leq h \\
& =\kappa(-z+h), & & h / 2 \leq z \leq h-z_{0 s} \\
& =\kappa\left(z+z_{0 b}\right), & & 0 \leq z \leq h / 2 .
\end{aligned}
$$

\subsubsection{The $k$ - $\omega$ Model}

[24] The equation for the inverse turbulent timescale or turbulent "frequency", $\omega$, is [Wilcox, 1988]

$$
\frac{\partial \omega}{\partial t}=\frac{\partial}{\partial z}\left(\frac{\nu_{t}}{\sigma_{\omega}} \frac{\partial \omega}{\partial z}\right)+\frac{\omega}{k}\left(c_{\omega 1} \nu_{t}\left(\left(\frac{\partial u}{\partial z}\right)^{2}+\left(\frac{\partial v}{\partial z}\right)^{2}\right)-c_{\omega 2} \varepsilon\right) .
$$

The parameters used in equation (15) were those defined by Wilcox [1988]: $\sigma_{\omega}=2, c_{\omega 1}=0.56$ and $c_{\omega 2}=0.83$. For the $k$ $\omega$ model $\varepsilon$ is defined as

$$
\varepsilon=\left(c_{\mu}^{0}\right)^{4} k \omega
$$

The empirical constants used in equations (5)-(7) and (16) were $c_{\mu}^{0}=0.5447$ and $\sigma_{k}=2$ [Wilcox, 1988].

[25] In order to define the surface boundary conditions for equation (15) L. Umlauf et al. (GOTM Sourcecode and Test case documentation, version 3.2, 2005, available at http:// www.gotm.net/pages/documentation/manual/pdf/a4.pdf) used the concept of power laws, which describe the decay of $k$ and the increase in $l$ away from the water surface

$$
k=K\left(-z+h+z_{0 s}\right)^{a}, \quad l=L\left(-z+h+z_{0 s}\right),
$$

where $K, L$ and $a$ are constants. The surface boundary condition for the $\omega$ equation (equation (15)) is found by using equations (5), (6) and (16) to express $\left(\nu_{t} / \sigma_{\omega}\right)(\partial \omega / \partial z)$ in terms of $k$ and $l$. Subsequent substitution of the power laws (equation (17)) results in the expression (see http:// www.gotm.net/pages/documentation/manual/pdf/a4.pdf)

$$
-\frac{\nu_{t}}{\sigma_{\omega}} \frac{\partial \omega}{\partial z}=\frac{K(0.5 a-1)}{\sigma_{\omega}}(1.5 a-1)\left(-z+h+z_{0 s}\right)^{a-1}
$$

Here $K$ is computed from the surface boundary condition for the $k$ equation (equation (9)), i.e.,

$$
K=\left(-\frac{\sigma_{k} \alpha\left(u_{*_{w}}^{2}+v_{*_{w}}^{2}\right)^{3 / 2}}{c_{\mu} a L}\right)^{2 / 3} \frac{1}{z_{0 s}} .
$$



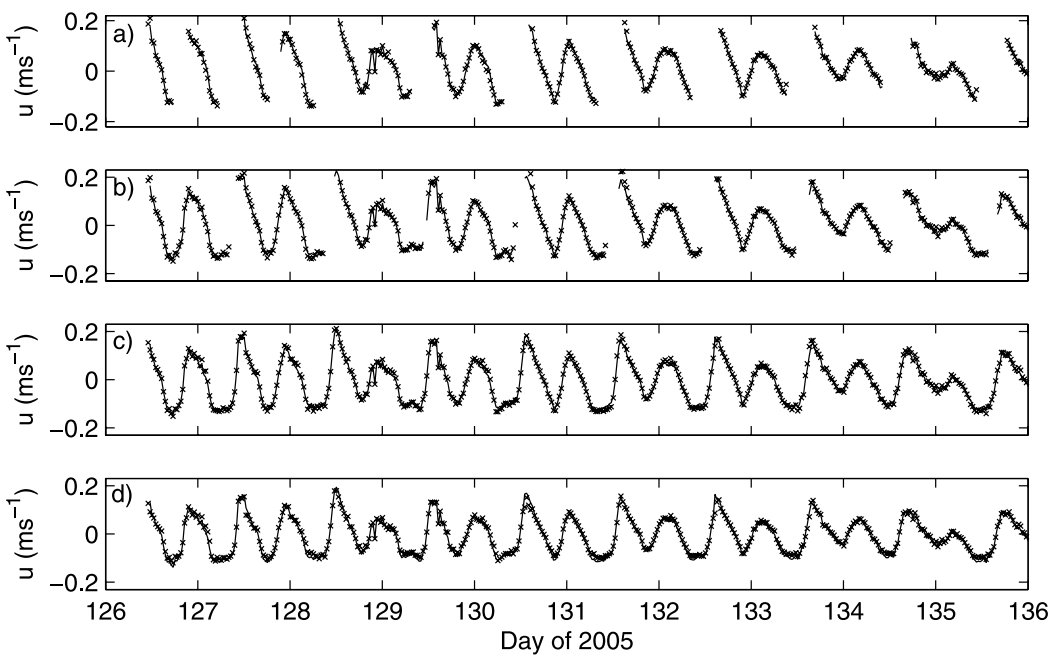

Figure 2. A $10 \mathrm{~d}$ subset of the time series of the simulated and measured streamwise current at heights of (a) 2, (b) 1.5 , (c) 0.5 , and (d) $0.15 \mathrm{~m}$ above the bed, corresponding to the ADV measurement locations. Shown are model results (line) and measurements (crosses) (k- $\omega$ model, $\alpha=60$, and $z_{0 s}=1.3 H_{s}$ ).

The parameters $a=-2.53$ and $L=0.25$ are derived by assuming a balance between dissipation and turbulent diffusion and using the power laws for $k$ and $l$ (equation (17)) as detailed by Umlauf et al. [2003]. In the absence of whitecapping the surface flux boundary condition is

$$
-\frac{\nu_{t}}{\sigma_{\omega}} \frac{\partial \omega}{\partial z}=\frac{k}{\sigma_{\omega}\left(-z+h+z_{0 s}\right)} .
$$

[26] At the bed the flux boundary condition for the $\omega$ equation is defined as

$$
-\frac{\nu_{t}}{\sigma_{\omega}} \frac{\partial \omega}{\partial z}=\frac{1}{\sigma_{\omega}} \frac{k}{\left(z+z_{0 b}\right)}
$$

\subsubsection{Model Implementation}

[27] The water column was divided into 200 intervals. A more finely resolved grid was used near the surface and bed to better resolve the boundaries [see Burchard, 2001]. The grid was staggered with the mean flow quantities located at the center of the intervals and the turbulent quantities at the interfaces of the intervals. The time stepping was equidistant and solved using a quasi-implicit method (for more details see Burchard and Petersen [1999]). A 1 s time interval was chosen to ensure numerical stability [Stips et al., 2005].

[28] The 1-D model was forced with the conditions observed during the Grizzly Bay field experiment (for more details see Jones and Monismith [2008]), in order to judge the ability of the turbulence closure models to simulate the distribution of $\varepsilon$ measured during the experiment. The measured water depth, wind stress, bottom roughness and depth-averaged current were used to force the model. The model used the measured depth-averaged current to find the appropriate pressure gradient, as described by Burchard [1999]. The bottom roughness was adjusted to match the observed bed stress, thereby accounting for enhanced stresses when waves reached the bed. $\alpha$ was defined to be 60 as this was found to best describe the relationship between the calculated wind energy input to the waves and $u_{*_{w}}^{3}$ for the Grizzly Bay measurements [see Jones and Monismith, 2008]. The sensitivity of the models results, to the choice of the parameter $z_{0 s}$ was explored. Each "condition" was run to steady state and turbulence and mean flow parameters were output by the model.

\subsection{Assessing Model Performance}

[29] Three methods were used to compare the quantitative agreement between the simulations and observations. The index of agreement, $I A$, for each model parameter $X$ is defined as [Willmott, 1982]

$$
I A=1-\frac{\sum\left|X_{\text {model }}-X_{o b s}\right|^{2}}{\sum\left(\left|X_{\text {model }}-\overline{X_{o b s}}\right|+\left|X_{o b s}-\overline{X_{o b s}}\right|\right)^{2}},
$$

where the overbar denotes a time mean. Perfect agreement between the model results and observations will yield an $I A$ of one and complete disagreement yields an $I A$ of zero. The index of agreement does not allow the identification of bias in the model output, therefore the percent model deviation from the observed mean was also calculated (i.e., $\left.\overline{X_{\text {model }}-X_{\text {obs }}} /\left|\overline{X_{o b s}}\right|\right)$. The third method employed was linear regression analysis between the measured and simulated data [e.g., Stips et al., 2005].

$$
X_{\text {model }}=a_{1} X_{o b s}+a_{0}
$$

Perfect agreement between measurements and simulations will produce a slope, $a_{1}=1$, an offset, $a_{0}=0$ and a correlation coefficient, $r=1$.

\section{Results}

\subsection{Mean Currents}

[30] Buoyancy production was assumed to be negligible for the simulations, therefore periods of data collected when the water column mean buoyancy frequency exceeded $1 \times$ $10^{-4} \mathrm{~s}^{-2}$ (indicating stratification) or the estimated buoy- 
Table 1. Index of Agreement and Linear Regression Analysis Between Measured and Simulated Streamwise Velocity $u^{\text {a }}$

\begin{tabular}{|c|c|}
\hline & Value \\
\hline$I A u \mathrm{ADV} 1$ & 0.995 \\
\hline IA $u$ ADV2 & 0.997 \\
\hline$I A u \mathrm{ADV} 3$ & 0.996 \\
\hline IA $u$ ADV4 & 0.994 \\
\hline$a_{0}$ & -0.003 \\
\hline$a_{1}$ & 0.95 \\
\hline$r^{2 \mathrm{~b}}$ & 0.99 \\
\hline
\end{tabular}

${ }^{\text {a}}$ Values are for $k-\omega$ model, $\alpha=60$, and $z_{0}=1.3 H_{s} . I A$ means index of agreement.

${ }^{\mathrm{b}}$ The $p$ values indicate that the correlation is significant for each of the fits at the $95 \%$ confidence level.

ancy production was greater than $1 \times 10^{-7} \mathrm{~m}^{2} \mathrm{~s}^{-3}$ (indicating significant convective cooling), were removed from the analysis. Furthermore, Jones and Monismith [2008] showed that on a number of occasions $\varepsilon$ measurements close to the bed were less than predicted by shear production due to the bed stress. It was hypothesized that this was due to the presence of stable suspended sediment stratification close to the bed. Including the effects of stratification due to sediment was beyond the scope of these simulations, therefore data where $\varepsilon$ was less than predicted by shear production due to the bed stress were removed from the analysis. 1373 data points remained for comparison with the model output.

[31] Excellent agreement between the measured and simulated mean current profiles was achieved for all of the turbulence models. This was not surprising as the measured depth-averaged currents were used to find the appropriate pressure gradient (section 2.2.4). An example of a time series of the measured and simulated streamwise velocity (Figure 2) demonstrates that velocities of both flood and ebb tides were closely reproduced at the four depths of the measurements. The respective $I A$ and linear regression values (in this case for the $k-\omega$ model) concur (Table 1). The $I A$ was very close to 1 and the linear regression resulted in a slope, $a_{1}$, close to 1 , an offset, $a_{0}$, very close to 0 and $r^{2}$ $\sim 1$. A representative example of the vertical profiles of mean velocity is shown in Figure 3 .

[32] The increased mixing close to the surface due to wave breaking leads to smaller gradients in the mean velocity close to the water surface [Craig, 1996]. Figure 3b illustrates the change in surface shear under whitecapping conditions. However, measurements could only be made below the trough of the waves. Therefore comparison of simulations with and without the surface TKE flux with the observations indicated no discernable difference between the ability of the model to reproduce the observed mean velocities.

\subsection{Dissipation of Turbulent Kinetic Energy}

[33] Without the inclusion of the surface TKE flux to simulate the wave breaking, the model failed to reproduce the measured $\varepsilon$ in the upper water column (Figures $3 \mathrm{a}$ and 4 and Table 2). To allow assessment of the model performance at different positions in the water column the $I A$ for $\varepsilon$ was calculated for three different depth intervals: $0-0.75 \mathrm{~m}$, $0.75-1.5 \mathrm{~m}$ and greater than $1.5 \mathrm{~m}$ below the water surface. Scatterplots of measured and modeled $\varepsilon$ and the percent deviation of the model mean from the observed mean further highlight any biases the model produced as a function of depth below the mean water level (BWL). As indicated in Figure 4, a better agreement between measured and simulated $\varepsilon$ was found for the measurements closer to the bed (Table 2). Close to the bed the influence of wave breaking was generally small, leading to more $\varepsilon$ measurements scaling with shear production due to the bed stress. a)

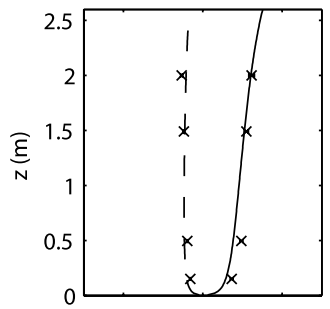

b)

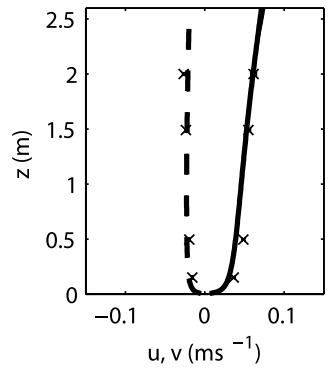

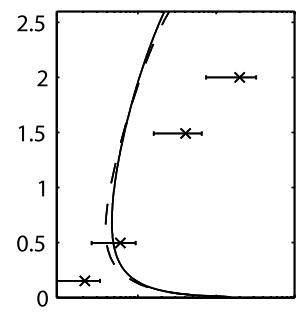
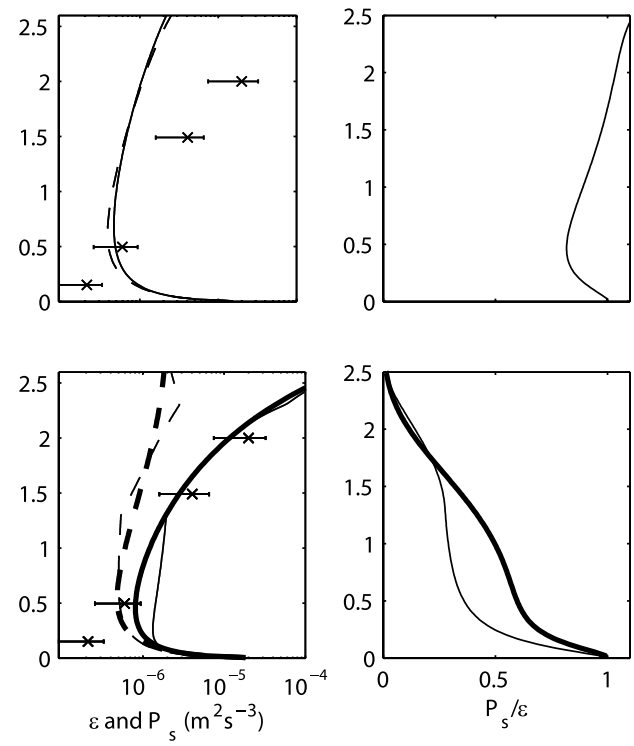

Figure 3. Vertical profiles of mean velocity $u$ (solid line) and $v$ (dashed line), dissipation $\varepsilon$ (solid line), and shear production $P_{s}$ (dashed line) and ratio $P_{s} / \varepsilon$ for a flood tide with a moderate following wind stress: (a) modeled without wave breaking and (b) modeled with wave breaking for $k$ - $\omega$ model $z_{0 s}=1.3 H_{s}$ (thick lines) and modified CB model $z_{0 s}=0.8 H_{s}$ (thin lines). Shown are observations of mean velocity and dissipation (crosses) with error bars showing uncertainty in measurements at $95 \%$ confidence level. 


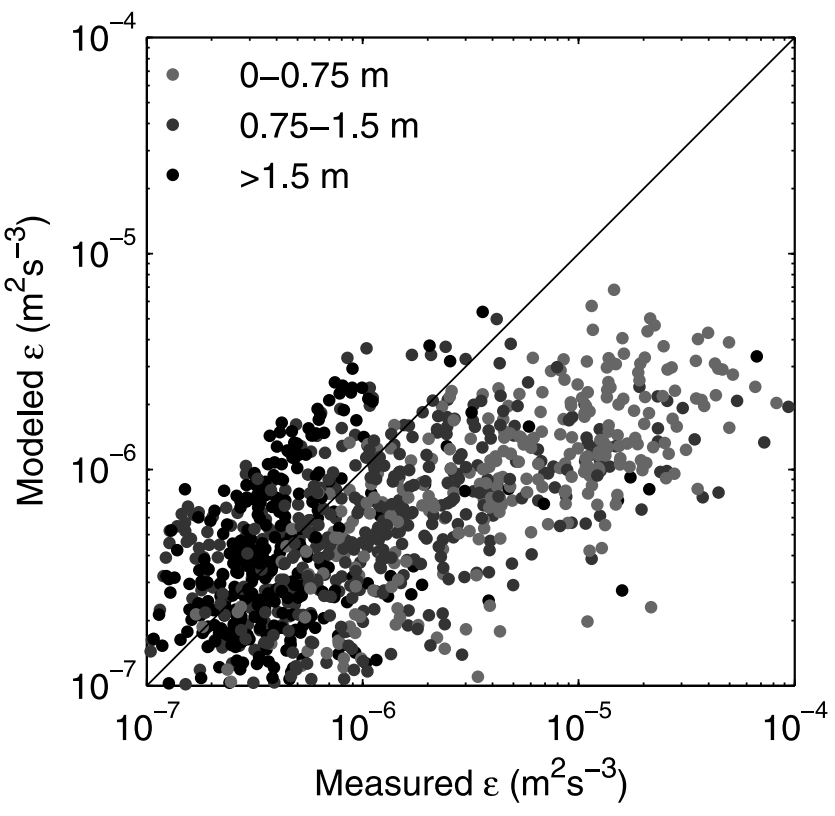

Figure 4. Scatterplot of measured and simulated $\varepsilon$ for the $k-\omega$ model with no surface TKE flux.

As expected, the influence of whitecapping waves was significant and must be included in the model in order to successfully reproduce the field measurements (Figure $3 b$ ). A time series comparison of measured and simulated $\varepsilon$ both with and without the surface TKE flux is shown in Figure 5.

[34] It was identified by Jones and Monismith [2008] that whitecapping was initiated at a wind speed of approximately $5 \mathrm{~m} \mathrm{~s}^{-1}$ for the Grizzly Bay conditions. However, insufficient $\varepsilon$ measurements were made close to the surface during weak wind events to ascertain the critical wind velocity, below which the TKE flux at the boundary should be set to zero and the surface of the water column modeled as a wind stress log layer.

[35] A series of runs were performed to assess the ability of the three turbulence models introduced in section 2.2 to model the influence of wave breaking in a shallow, windand tide-forced environment. The parameter $z_{0 s}$ was altered in order to assess the sensitivity of the model to this parameter as well as to optimize its choice. A selection of these runs, chosen to demonstrate the differences in the models and their parameterization are presented here.

[36] The Craig and Banner (CB) model with $z_{0 s}=H_{s}$ improved the agreement between observations and model in the interval $0-0.75 \mathrm{~m}$ BWL compared with the model without wave breaking (Table 2). However, the $I A$ was smaller for the CB model with $z_{0 s}=H_{s}$ than for the no wave breaking model for depths greater than $0.75 \mathrm{~m}$. When $z_{0 s}$ was reduced to $0.3 H_{s}$, better agreement was achieved throughout the water column. However, although the $I A$ for depths greater than $1.5 \mathrm{~m}$ BWL was improved with this parameterization of $z_{0 s}$, the measurements close to the bed continued to be over predicted (Figure 6 and Table 2). The $I A$ for depths $>1.5 \mathrm{~m}$ BWL changed from 0.6 to 0.82 , however, the percent deviation of the model mean from the observed mean remained reasonably large and positive (3.4\%). The CB model rate of decay of wave breaking induced turbulence was not rapid enough, leading to elevated levels of $\varepsilon$ at depth.

[37] The modified CB $(\bmod \mathrm{CB}) \operatorname{model}$ with $z_{0 s}=0.8 H_{s}$ resulted in similar $I A$ values to the $\mathrm{CB}$ model with $z_{0 s}=$ $0.3 H_{s}$ at all depths (Table 2 and Figure 7). The percent deviation of the model mean from the observed mean was closer to zero in the upper water column, however, for depths $>1.5 \mathrm{~m}$ BWL the positive bias remained (3.7\%). The linear regression analysis indicated that the modified $\mathrm{CB}$ model was an improvement over the $\mathrm{CB}$ model as $a_{0}$ and $a_{1}$ were closer to 0 and 1 respectively and the $r^{2}$ value was higher. Figure 3 contains an example of the profiles of mean velocity, dissipation and shear production. The modified CB model overpredicted the dissipation close to the bed.

[38] For the $k-\omega$ model $z_{0 s} / H_{s}=1.3$ most accurately replicated the $\varepsilon$ measurements (Figure 8). For this case a high and approximately equal value of the $I A$ was achieved for each depth interval and the percent deviation of the model mean from the observed mean was small at all depths. Although the $I A$ was slightly larger for depths $>1.5 \mathrm{~m}$ BWL compared with the $\mathrm{CB}$ and modified $\mathrm{CB}$ models the difference was not significant at the $90 \%$ confidence level. However, the percent deviation of the model mean from the observed mean was significantly decreased. The $k-\omega$ model produced a faster decay of $\varepsilon$

Table 2. Results of the Comparative Linear Regression Analysis and Index of Agreement Analysis Between the Logarithm of Measured and Simulated TKE Dissipation Rates ${ }^{\mathrm{a}}$

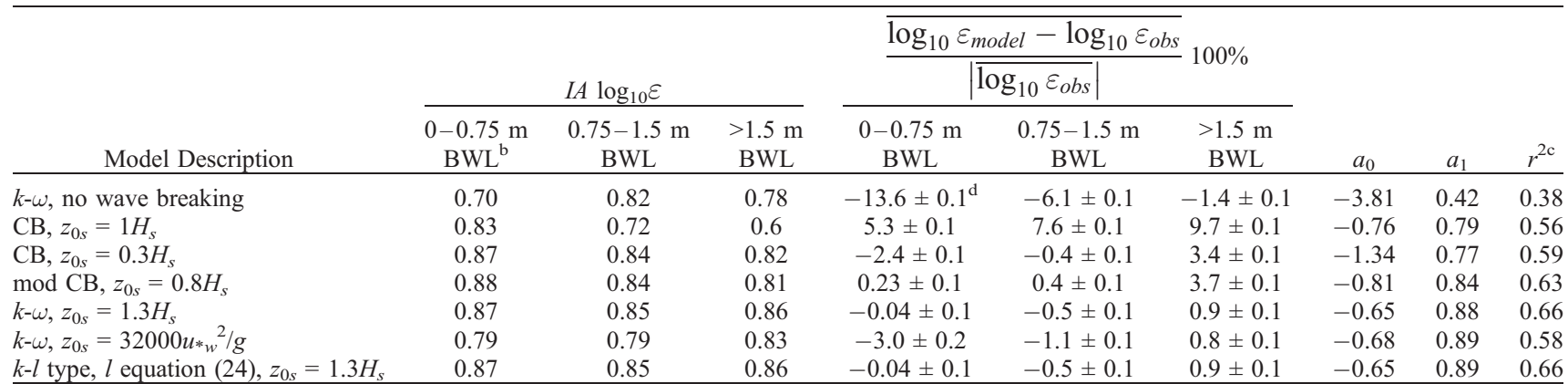

${ }^{\mathrm{a}} \mathrm{IA}$ is index of agreement; $90 \%$ confidence intervals for IA are $0.940 I A \leq I A \leq 1.066 \mathrm{IA}$, assuming $\log _{10} \varepsilon$ is sampled from a normal population [Emery and Thomson, 2001].

${ }^{\mathrm{b}} \mathrm{BWL}$ means below mean water level.

${ }^{\mathrm{c}}$ The $p$ values (not shown) indicate that the correlation is significant for each of the fits at the $95 \%$ confidence level.

${ }^{\mathrm{d}}$ Confidence intervals are shown at the $95 \%$ confidence level. 


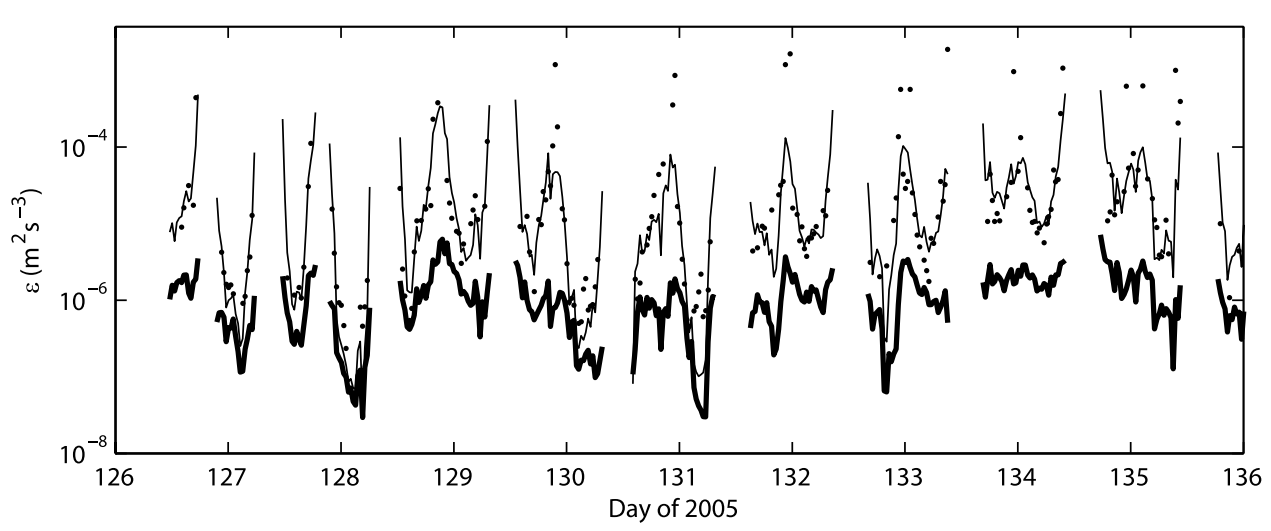

Figure 5. A $10 \mathrm{~d}$ subset of the time series of TKE dissipation rate $2 \mathrm{~m}$ above bed, measured (circles), simulated without surface TKE flux (thin line), and simulated with surface TKE flux (thick line).

because of wave breaking so measurements in the lower water column were better predicted (Table 2). The linear regression of the logarithm of the measured and simulated $\varepsilon$ achieved a slope of 0.88 and intercept of -0.65 with $r^{2}=$ 0.66 .

[39] Alternative parameterizations for $z_{0 s}$ include the Charnock-type expression (equation (1)). Comparison of model results with measurements indicated that $a_{s}=32000$ was a suitable choice for the Grizzly Bay conditions. The model $I A$ and linear regression analysis revealed that the Charnock-type parameterization did not replicate the measurements as well as assuming $z_{0 s}$ is proportional to the significant wave height (Table 2). $a_{s}=32000$ is similar in magnitude to $a_{s}=1.4 \times 10^{4}$ found by Stips et al. [2005] for wave age $\left(c_{p} / u_{* a}\right) 14$ to 24 and $a_{s}=\mathrm{O}\left(10^{5}\right)$ found by Stacey [1999] for wave ages greater than 25 .

[40] In conclusion, comparison with the Grizzly Bay data set identified the $k-\omega$ model, with $\alpha=60$ and $z_{0 s}=1.3 H_{s}$, as the most suitable for simulating the influence of wave

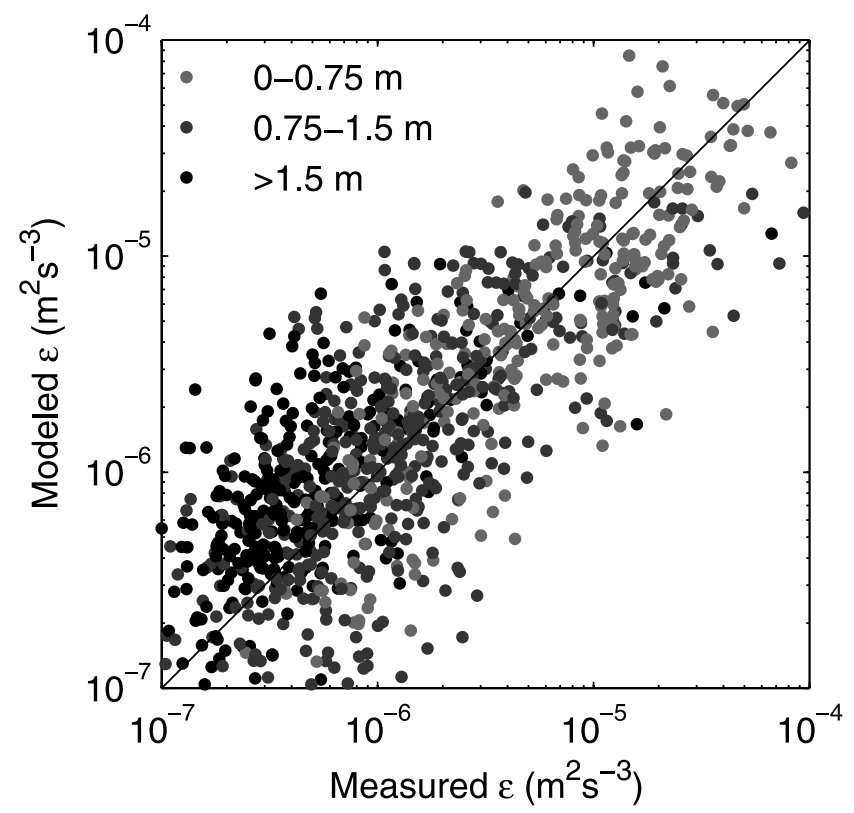

Figure 6. Scatterplot of measured and simulated $\varepsilon$ for the CB model, $\alpha=60$ and $z_{0 s}=0.3 H_{s}$. breaking in a shallow water, tide- and wind-forced environment. This compares with $z_{0 s}=H_{s}$ found by Umlauf et al. [2003] to describe the SWADE [Terray et al., 1996] and WAVES [Drennan et al., 1996] data sets reasonably well for the $k-\omega$ model with $\alpha=100$. Further measurements, in particular above wave troughs, are required in order to correctly describe $z_{0 s}$ for a wide range of wave age conditions.

\section{Discussion}

[41] It has been noted that the reference point for the distance below the water surface varies between field experiments and numerical models [e.g., Banner et al., 2002; Burchard, 2001; Gemmrich and Farmer, 2004; Soloviev and Lukas, 2003]. Field studies in which instruments are stationary reference the mean water level. One-dimensional numerical models use a virtual flat surface as the upper boundary that is implied to be the mean water surface.

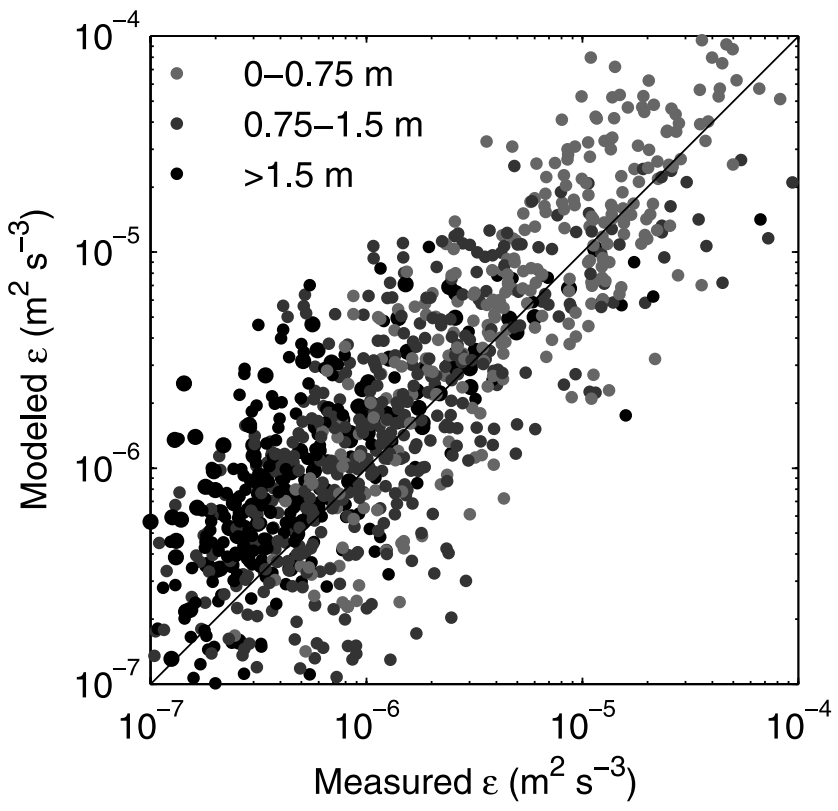

Figure 7. Scatterplot of measured and simulated $\varepsilon$ for the modified CB model, $\alpha=60$ and $z_{0 s}=0.8 H_{s}$. 


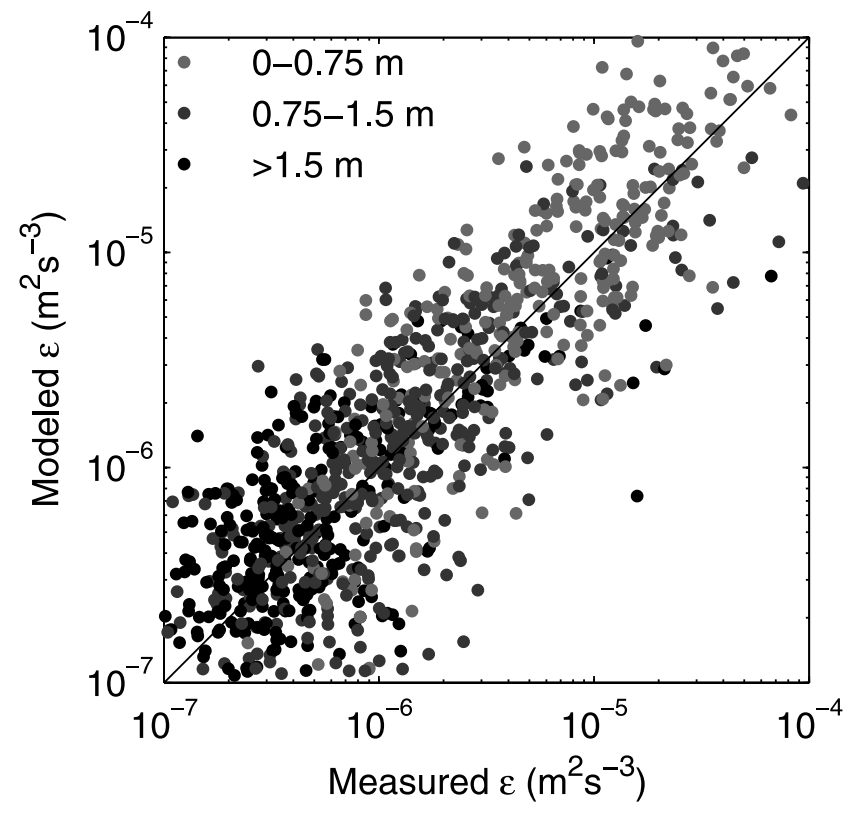

Figure 8. Scatterplot of measured and simulated $\varepsilon$ for the $k-\omega$ model, $\alpha=60$ and $z_{0 s}=1.3 H_{s}$.

However, the wave-following measurements of Gemmrich and Farmer [2004], that resolved $\varepsilon$ because of whitecapping at different phases of the wave, show that on average higher $\varepsilon$ occurs under the crest of the wave as opposed to the trough region, at a ratio of $\varepsilon_{\text {crest }} / \varepsilon_{\text {trough }} \approx 1.6$. Therefore, in order to compare the model output, which represents an average condition over many wave cycles, with $\varepsilon$ measurements from a stationary instrument, Gemmrich and Farmer [2004] argue that the model origin should correspond to the location of the mean $\varepsilon$. Gemmrich and Farmer [2004] found that the location of mean $\varepsilon$ is approximately halfway between the mean water line and the significant wave crests. However, it is not possible to implement such an adjustment in the model origin when simulating a tide- and wind-forced shallow water column, therefore the selection of $z_{0 s}$ in this study was influenced by the higher $\varepsilon$ under the wave crests.

[42] Comparison of model output and observations showed that the surface turbulent kinetic energy flux did not decay rapidly enough with depth below the water surface for both the CB model and the modified CB model, resulting in the overestimation of $\varepsilon$ at depth. The $k-\omega$ model achieved better agreement between the observations and model at depth. The disparity between the turbulent length scale formulations adopted in the $\mathrm{CB}$ and modified $\mathrm{CB}$ models (equations (13) and (14)) and the turbulent length scale profile calculated by the $k$ - $\omega$ model is shown in Figure 9. Close to the water surface the $k-\omega$ model predicts the turbulent length scale to increase approximately linearly with a proportionality constant of $L=0.25$ (equation (17)). This agrees with the Umlauf et al. [2003] analytical result derived from the $k$ - $\omega$ model under the assumption that turbulent diffusion balances dissipation. In comparison, the $\mathrm{CB}$ and modified CB models assume $L=\kappa=0.4$. Extending from the bed the $k-\omega$ model turbulent length scale increases linearly with the proportionality constant approximately equal to $\kappa=0.4$ agreeing with the $\mathrm{CB}$ and modified CB models.
[43] The turbulent length scale output by the $k$ - $\omega$ model can be approximated by a bilinear relationship (shown in Figure 9)

$$
\begin{gathered}
l=0.25\left(-z+z_{0 s}+h\right), \quad\left[0.25\left(h+z_{0 s}\right)-\kappa z_{0 b}\right] /(\kappa+0.25) \\
\leq z \leq h \\
=\kappa\left(z+z_{0 b}\right), \quad 0 \leq z \leq\left[0.25\left(h+z_{0 s}\right)-\kappa z_{0 b}\right] \\
/(\kappa+0.25) .
\end{gathered}
$$

Equation (24) is a more appropriate choice for the prescribed turbulent length scale under whitecapping conditions for use in a $k-l$ type turbulence closure model. Employing this prescribed turbulent length scale formulation resulted in excellent agreement between the model predictions and measurements (Table $2, k-l$ type, $l$ equation (24)).

[44] The Grizzly Bay data set demonstrated that under conditions of whitecapping waves the shallow, wind- and tide-forced water column is best described by a three layer structure, in which the layers are termed the wave breaking layer, transition layer and bottom log layer, from the water surface downward (Figure 10) [Jones and Monismith, 2008]. In the wave breaking layer, $\varepsilon$ and transport of TKE are in balance. In the transition layer, the transport of TKE dominates shear production $\left(P_{S}\right)$ and $\varepsilon$ decays as $z^{\prime-2}$, following the deep water wave breaking scaling developed by Terray et al. [1996]. Finally, in the bottom log layer, shear production due to the tide pressure gradient is the dominant source of TKE. In this layer $P_{S}$ and $\varepsilon$ are in balance. The wind stress log layer was found to be absent, in the presence of whitecapping at the Grizzly Bay measurement location. This structure differs from that found by Feddersen et al. [2007] at a nearshore location. Here

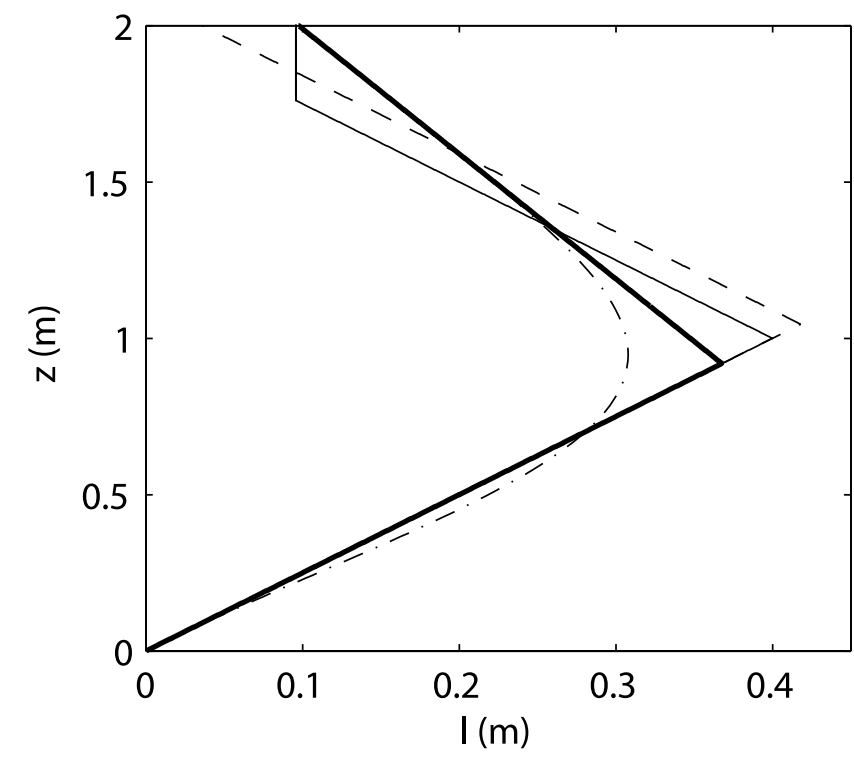

Figure 9. Turbulent length scale 1 for $k-\omega$ model, $z_{0 s}=$ $1.3 H_{s}$ (dash-dotted line); $\mathrm{CB}$ model, $z_{0 s}=0.3 H_{s}$ (equation (13)) (dashed line); modified CB model, $z_{0 s}=0.8 H_{s}$ (equation (14)) (solid thin line); and linear approximation to $k$ - $\omega$ model (equation (24)) (solid thick line) for $H_{s}=0.3 \mathrm{~m}$. 


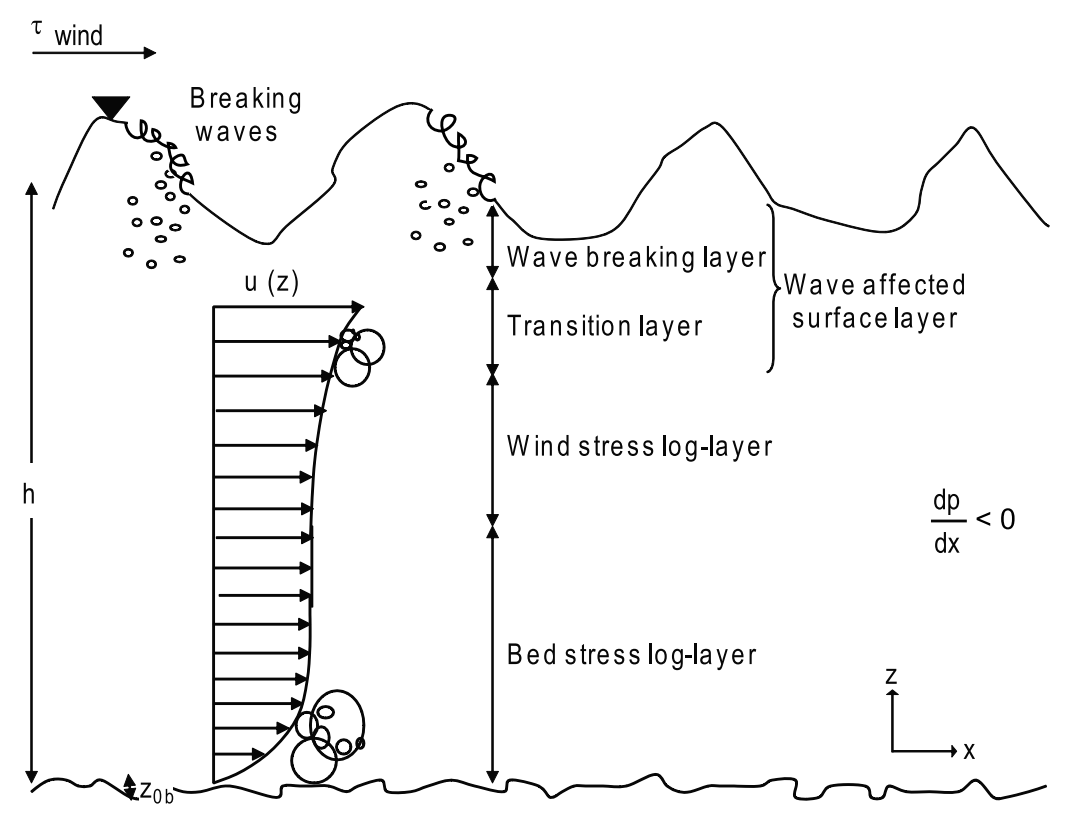

Figure 10. Schematic overview of the vertical structure of a shallow water column resulting from the combined forcing of a wind stress and tide pressure gradient.

measurements of $\varepsilon$ near the surface followed the deep water wave breaking scaling, however, $\varepsilon$ near the bed did not scale with shear production due to the bed stress. Instead, Feddersen et al. [2007] showed that the increase in $\varepsilon$ was likely due to the decrease in turbulent length scale close to the bed.

[45] Simulations with the $k-\omega$ model (with $z_{0 s}=1.3 H_{s}$ and $\alpha=60$ ) provided detailed vertical resolution of the mean and turbulent flow variables, allowing the layers to be readily identified for different forcing conditions. A representative example of the vertical profiles of mean velocity, $P_{s}$ and $\varepsilon$ under conditions of a flood tide in the presence of a following wind stress is shown in Figure 3. $P_{s}$ and $\varepsilon$ were balanced throughout the water column when wave breaking was not modeled. When wave breaking was included in the model $\varepsilon$ exceeded $P_{s}$ to a large depth. The bed stress log layer occupied a height of only $0.1 \mathrm{~m}$ above the bed. No wind stress log layer was present.

[46] The ratio of $P_{s}$ to $\varepsilon$ was used to study the structure of the water column for the duration of the simulations (Figure 11). A ratio of $P_{s} / \varepsilon \sim 1$, indicates either a bed stress $\log$ layer and/or a wind stress log layer. A ratio of $P_{s} / \varepsilon \sim 0$ extending from the surface downward, indicates the presence of a wave-affected surface layer. The bed stress and surface stress are also shown in Figure 11 to show the physical forcing which produced the resulting vertical structure of $P_{s}$ and $\varepsilon$. Smaller bed shear stresses during ebb tides led to smaller bed stress log-law layers than during flood tide, for a similar magnitude wind stress. During times of large surface stress the wave-affected layer extended over a large part of the water column and often extended to the bottom boundary layer, excluding the wind stress log-law layer. During periods of weak surface stresses the ratio of $P_{s}$ to $\varepsilon$ was close to one over the most of the water column.

[47] Comparison between the relative magnitudes of $P_{s}$ to $\varepsilon$ and consideration of the velocity shear allows the transi- tion depth between each of the layers to be identified for the duration of the measurements. Local maxima in the magnitude of velocity shear allowed identification of a transition between the bed shear stress layer and wind stress layer where $P_{s} / \varepsilon$ does not deviate from one. During the times that the water column was unstratified, $93 \%$ of the simulations resulted in the wave-affected surface layer overlapping with the bottom boundary layer, and $7 \%$ of the simulations had a distinct wind stress log layer. Figure 12 illustrates the depth of penetration of the wave-affected surface layer as a fraction of the total water column height for the $93 \%$ of occasions when the wave-affected surface layer overlapped with the bed stress log layer. The histogram demonstrates that the wave-affected surface layer often extended over the full depth of the water column.

[48] As shown by Jones and Monismith [2008], the height above the bed where the bottom log layer transitions to the transition layer, $z_{t}$, can be estimated by equating the deep water wave breaking scaling relationship, $\varepsilon H_{S} /\left(\alpha u_{*_{w}}^{3}\right)$ $=0.2\left(z^{\prime} / H_{s}\right)^{-2}$, and the scaling relationship for the bottom boundary layer, $\varepsilon=u_{* b}^{3} / \kappa z$, giving

$$
z_{t}=\frac{-\left(0.2 \alpha \kappa H_{s} \frac{u_{*_{w}}^{3}}{u_{*_{b}}^{3}}+2 h\right)+\sqrt{\left(0.2 \alpha \kappa H_{s} \frac{u_{*_{w}}^{3}}{u_{*_{b}}^{3}}+2 h\right)^{2}-4 h^{2}}}{-2} .
$$

Comparison of the model predictions of the transition height with equation (25) demonstrates that the simple scaling argument achieved good predictions of the depth of influence of wave breaking (Figure 13).

[49] Models of sediment transport and phytoplankton dynamics often require the vertical turbulent diffusivity as input. The $k-\omega$ model was used to demonstrate the influence of whitecapping on the vertical profile of the turbulent 

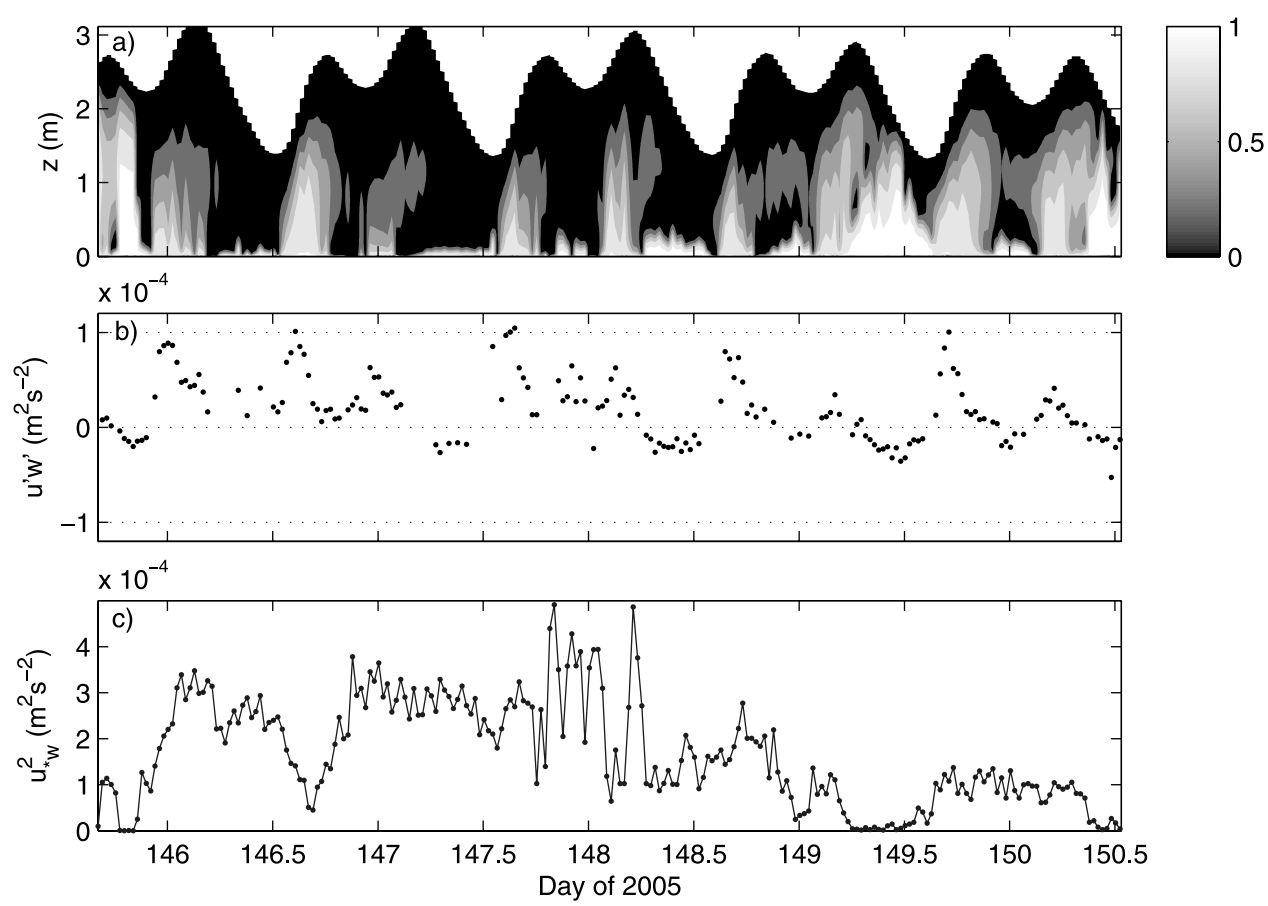

Figure 11. A $5 \mathrm{~d}$ subset of the relative distribution of shear production of TKE and dissipation of TKE as modeled for the field conditions. (a) Ratio of shear production $P_{s}$ to dissipation $\varepsilon$, (b) bed shear stress (positive flood tide), and (c) surface shear stress due to wind.

diffusivity. A bed shear stress alone created the familiar parabolic turbulent diffusivity profile with a maximum at midwater column depth and minima at the surface and bed (Figure 14). The addition of a shear stress at the surface due to the wind, led to the superposition of two parabolic distributions (Figure 14). The addition of wave breaking led to enhanced turbulent diffusivity at the surface which decayed with depth (Figure 14). These simulations indicate that without the inclusion of the influence of whitecapping in numerical models, the turbulent diffusivity could be underestimated over much of a shallow water column,

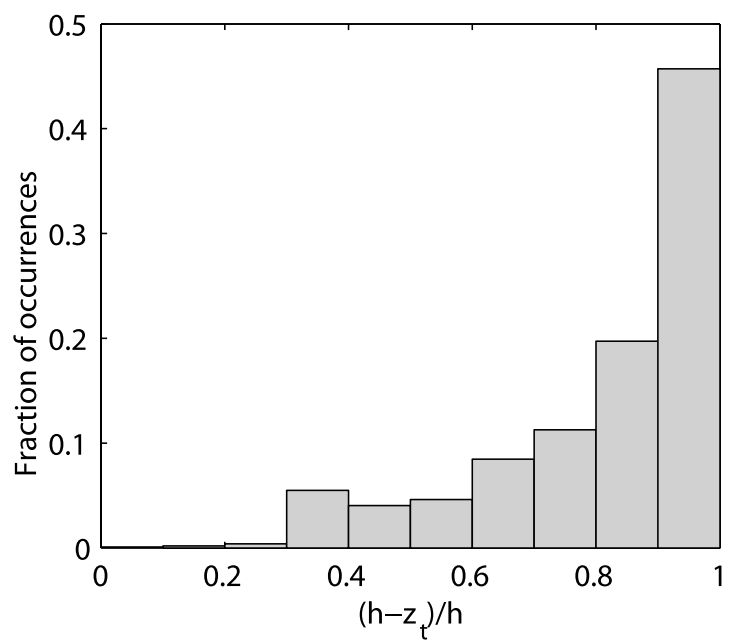

Figure 12. Depth of penetration of the wave-affected surface layer as a fraction of the total water column height for the $93 \%$ of occasions when the wave-affected surface layer overlapped with the bed stress boundary layer. resulting in errors in the simulation of phytoplankton and sediment dynamics.

\section{Summary and Conclusions}

[50] It has been shown that profiles of $\varepsilon$ and mean velocity under conditions of whitecapping waves in a shallow tide- and wind-driven environment can be repro-

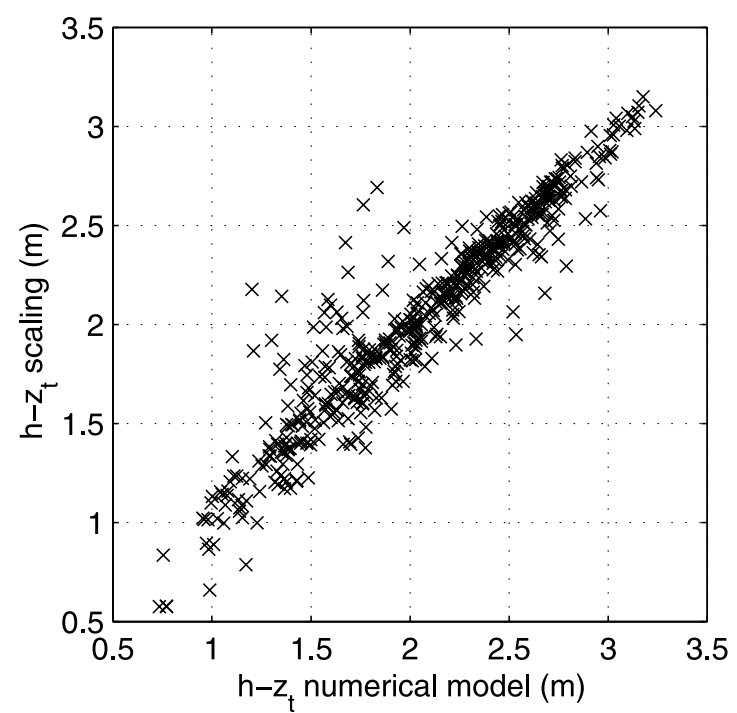

Figure 13. Comparison between transition depth $z_{t}$ between the wave-affected surface layer and the bed stress boundary layer as predicted by the numerical model and the scaling equations introduced in section 3.7. 


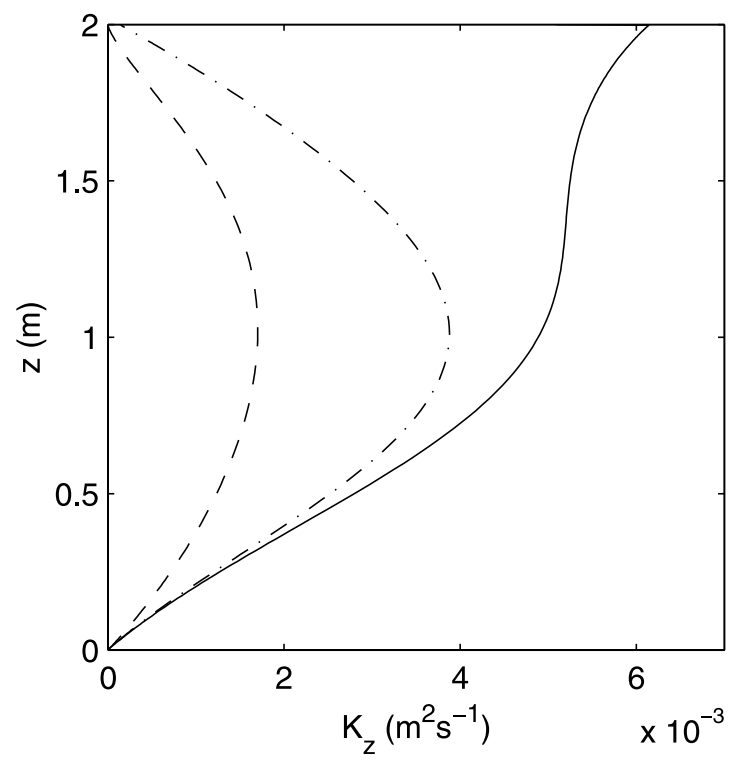

Figure 14. Examples of turbulent diffusivity profiles for forcing conditions including a bed stress (dashed line), bed stress plus wind stress (dash-dotted line), and bed stress plus wind stress plus wave breaking (solid line); $u_{*_{w}}=0.012 \mathrm{~m}$ $\mathrm{s}^{-1}$ and $u_{* b}=6 \times 10^{-3} \mathrm{~m} \mathrm{~s}^{-1}$.

duced by a 1-D numerical model. The $k$ - $\omega$ turbulence model was found to best replicate the measured decay of $\varepsilon$ with depth. The most critical model input parameter is the surface roughness length, $z_{0 s}$, comparison of measurements and model found that $z_{0 s}=1.3 H_{s}$ or $z_{0 s}=32000 u_{*_{w}}^{2} / g$ were the optimal choices for the $k-\omega$ model with $\alpha=60$, for the Grizzly Bay conditions. The Craig and Banner [1994] model achieved equally as good reproduction of the observations as the $k-\omega$ model when the proportionality constant in the prescribed linear length scale relationship for the upper half of the water column was modified from the traditionally employed von Karman's constant, $\kappa=0.4$, to 0.25 . Further measurements are required in order to correctly describe $z_{0 s}$ for a wide range of wave age conditions. The Grizzly Bay measurements and the 1-D simulations of the physics have shown that the effects of wave-breaking induced mixing are likely to be critical to the dynamics of suspended sediment and phytoplankton biomass.

[51] Acknowledgments. Thanks are due to F. Parchaso, B. Richards, and J. Thompson from the U.S. Geological Survey for assistance with the field experiment. We would also like to thank K. Davies, D. Fong, S. Giddings, J. Hench, R. Lowe, C. McDonald, N. Nidzieko, J. Rosman, U. Shavit, J. Steinbuck, and C. Troy for their help in collecting the field data set. The manuscript benefited from comments from two anonymous reviewers. The work was generously supported by the CALFED Bay Delta Authority Restoration Program (ERP02P22) and the Foundation for Young Australians Centenary Scholarship Award.

\section{References}

Agrawal, Y. C., E. A. Terray, M. A. Donelan, P. A. Hwang, A. J. Williams, W. M. Drennan, K. K. Kahma, and S. A. Kitaigorodskii (1992), Enhanced dissipation of kinetic-energy beneath surface-waves, Nature, $359,219-220$.

Anis, A., and J. N. Moum (1992), The superadiabatic surface-layer of the ocean during convection, J. Phys. Oceanogr, 22, 1221-1227.

Anis, A., and J. N. Moum (1995), Surface wave-turbulence interactionsScaling epsilon(z) near the sea-surface, J. Phys. Oceanogr., 25, $2025-$ 2045 .
Banner, M. L., J. R. Gemmrich, and D. M. Farmer (2002), Multiscale measurements of ocean wave breaking probability, J. Phys. Oceanogr. $32,3364-3375$.

Burchard, H. (1999), Recalculation of surface slopes as forcing for numerical water column models of tidal flow, Appl. Math. Comput., 23, 737755 .

Burchard, H. (2001), Simulating the wave-enhanced layer under breaking surface waves with two-equation turbulence models, J. Phys. Oceanogr., $31,3133-3145$

Burchard, H., and O. Petersen (1999), Models of turbulence in the marine environment-A comparative study of two-equation turbulence models, J. Mar. Syst., 21, 29-53.

Cheung, T. K., and R. L. Street (1988), The turbulent layer in the water at an air water interface, J. Fluid Mech., 194, 133-151.

Craig, P. D. (1996), Velocity profiles and surface roughness under breaking waves, J. Geophys. Res., 101, 1265-1277.

Craig, P. D., and M. L. Banner (1994), Modeling wave-enhanced turbulence in the ocean surface-layer, J. Phys. Oceanogr., 24, 2546-2559.

Donelan, M. A. (1990), Air-sea interaction, in Ocean Engineering Science, edited by B. LeMehaute and D. M. Hanes, pp. 239-292, John Wiley, New York.

Drennan, W. M., M. A. Donelan, E. A. Terray, and K. B. Katsaros (1996), Oceanic turbulence dissipation measurements in SWADE, J. Phys. Oceanogr., 26, 808-815.

Emery, W., and R. Thomson (2001), Data Analysis Methods in Physical Oceanography, Elsevier, New York.

Feddersen, F., and A. J. Williams (2007), Direct estimation of the Reynolds stress vertical structure in the nearshore, J. Atmos. Oceanic Technol., 24, $102-116$.

Feddersen, F., J. H. Trowbridge, and A. J. Williams (2007), Vertical structure of dissipation in the nearshore, J. Phys. Oceanogr., 37, 1764-1777, doi:10.1175/JPO3098.1.

Gemmrich, J. R., and D. M. Farmer (1999), Observations of the scale and occurrence of breaking surface waves, J. Phys. Oceanogr., 29, 25952606.

Gemmrich, J. R., and D. M. Farmer (2004), Near-surface turbulence in the presence of breaking waves, J. Phys. Oceanogr., 34, 1067-1086.

Jones, N. L., and S. G. Monismith (2007), Measuring short-period wind waves in a tidally forced environment with a subsurface pressure gauge, Limnol. Oceanogr. Methods, 5, 317-327.

Jones, N. L., and S. Monismith (2008), The influence of whitecapping waves on the vertical structure of turbulence in a shallow estuarine embayment, J. Phys. Oceanogr., doi:10.1175/2008JPO3766.1, in press.

Kundu, P. K. (1980), A numerical investigation of mixed-layer dynamics, J. Phys. Oceanogr., 10, 220-236.

Lumley, J. L., and E. A. Terray (1983), Kinematics of turbulence convected by a random wave field, J. Phys. Oceanogr., 13, 2000-2007.

Ly, L., and R. Garwood (2000), Numerical modeling of wave-enhanced turbulence in the oceanic upper layer, J. Oceanogr., 56, 473-483.

Mellor, G. L., and T. Yamada (1982), Development of a turbulence closure model for geophysical fluid problems, Rev. Geophys., 20, 851-875.

Munk, W. H., H. Charnock, M. S. Longuet-Higgins, and W. V. R. Malkus (1955), Wind stress on water: An hypothesis - Wind stress on a water surface, Q. J. R. Meteorol. Soc., 81, 639-640.

Osborn, T., D. M. Farmer, S. Vagle, S. A. Thorpe, and M. Cure (1992), Measurements of bubble plumes and turbulence from a submarine, $A t-$ mos. Ocean, 30, 419-440.

Rapp, R. J., and W. K. Melville (1990), Laboratory measurements of deepwater breaking waves, Philos. Trans. R. Soc. London, Ser. A, 331, 735800.

Rodi, W. (1987), Examples of calculation methods for flow and mixing in stratified fluids, J. Geophys. Res., 92, 5305-5328.

Soloviev, A., and R. Lukas (2003), Observation of wave-enhanced turbulence in the near-surface layer of the ocean during TOGA COARE, Deep Sea Res., Part I, 50, 371-395.

Stacey, M. W. (1999), Simulation of the wind-forced near-surface circulation in Knight Inlet: A parameterization of the roughness length, J. Phys. Oceanogr., 29, $1363-1367$.

Stips, A., H. Burchard, K. Bolding, H. Prandke, A. Simon, and A. Wuest (2005), Measurement and simulation of viscous dissipation in the wave affected surface layer, Deep Sea Res., Part II, 52, 1133-1155.

Terray, E. A., M. A. Donelan, Y. C. Agrawal, W. M. Drennan, K. K. Kahma, A. J. Williams, P. A. Hwang, and S. A. Kitaigorodskii (1996), Estimates of kinetic energy dissipation under breaking waves, J. Phys. Oceanogr., 26, 792-807.

Terray, E. A., W. M. Drennan, and M. A. Donelan (1999), The vertical structure of shear and dissipation in the ocean surface layer, paper presented at Symposium on the Wind-Driven Air-Sea Interface: Electromagnetic and Acoustic Sensing, Wave-Dynamics and Turbulent Fluxes, Univ. of N. S. W., Sydney, N. S. W., Australia. 
Umlauf, L., and H. Burchard (2003), A generic length-scale equation for geophysical turbulence models, J. Mar. Res., 61, 235-265.

Umlauf, L., and H. Burchard (2005), Second-order turbulence closure models for geophysical boundary layers: A review of recent work, Cont. Shelf Res., 25, 795-827.

Umlauf, L., H. Burchard, and K. Hutter (2003), Extending the k-omega turbulence model towards oceanic applications, Ocean Modell., 5, 195218.

Wilcox, D. C. (1988), Reassessment of the scale-determining equation for advanced turbulence models, AIAA J., 26, 1299-1310.

Willmott, C. J. (1982), Some comments on the evaluation of model performance, Bull. Am. Meteorol. Soc., 63, 1309-1313.
Young, I. R., M. L. Banner, M. A. Donelan, A. V. Babanin, W. K. Melville, F. Veron, and C. McCormick (2005), An integrated system for the study of wind-wave source terms in finite-depth water, J. Atmos. Oceanic Technol., 22, 814-831.

N. L. Jones, School of Environmental Systems Engineering, Mailstop MO15, University of Western Australia, 35 Stirling Highway, Crawley, WA 6009, Australia. (nicole.jones@uwa.edu.au)

S. G. Monismith, Environmental Fluid Mechanics Laboratory, Department of Civil and Environmental Engineering, Stanford University, Stanford, CA 94305 , USA. 